\title{
Knowledge of Health Care Providers on HPV Related Issues in Cervical Cancer.
}

\author{
F HUSSAIN $^{\mathrm{a}}$, MS FLORA ${ }^{\mathrm{b}}$, K NAHAR $^{\mathrm{c}}$, M KHAN $^{\mathrm{d}}$
}

\begin{abstract}
Summary:
Background: The field of cervical cancer prevention is rapidly evolving because of identification of Human Papilloma Virus (HPV) as the necessary cause of disease. HPV vaccines are now in the market.For successful triggering of cervical cancer prevention program, $\mathrm{HPV}$ informations should be communicated to health care providers whose understanding about HPV has lagged behind the scientific and technical advances.

Objective: The objective of this intervention study was to identify gap and educate health care providers delivering services to women and adolescents in Medical Colleges on $H P V$ related issues and vaccination.
\end{abstract}

Methods: The study was done from July 2007 to June 2008 where 3 advocacy workshops were conducted. The

Introduction :

Cervical Cancer is a major public health problem for developing countries. It is second most common cancer among women world wide, with an estimated 4,93,000 new cases and 2,74,000 deaths in $2002 .{ }^{1} 83 \%$ of these cases occur in developing countries ${ }^{1}$ Human Papilloma Virus (HPV) has been recognized as a necessary cases of cervical cancer ${ }^{2,3}$. It has been estimated that HPV 16 and 18 accounts for $70 \%$ of cervical cancer ${ }^{4}$. Genital HPV infection is sexually transmitted and any sexual activity poses a risk. No treatment of existing infections is available to reduce the duration of infection. After 15 years of extensive clinical trials on transmission dynamics of HPV, HPV vaccines have been invented

a. Farhat Hussain, Professor \& Head, Dept of Gynae Oncology, NICRH.

b. Meerjady Sabrina Flora, Associate Professor, Dept of Epidemiology, NIPSOM

c. Khairun Nahar, Assistant Professor, Dept of Obs \& Gynae, SSMC.

d. Mahbuba Khan, Medical Officer, Dept of Obs \& Gynae, SSMC. Address of Correspondence: Farhat Hussain, Professor \& Head, Dept of Gynae Oncology, NICRH.

Received: 16 May 2011

Accepted: 20 September 2011 knowledge level of 106 participants were assessed before and after intervention. Updated informations about HPV and vaccine was given to participants as intervention.

Results: Wide knowledge gap was identified among participants on HPV related insues, but significant improvement was observed following intervention. The pretest and post test score of knowledge was 28.09 and 38.60 respectively showing an average increase of 10 after intervention.

Conclusions: HPV education should be extensively disseminated to health care providers to obtain public health benefits of HPV vaccination program.

Key words : Cervical Cancer, Human Papilloma Virus (HPV), Health Care Providers.

(J Bangladesh Coll Phys Surg 2011; 29: 213-218)

which offers protection against HPV infection and resultant disease.

Acceptability and wide use of this new vaccine demands clear understanding about HPV infections, immunity, benefits and drawbacks of vaccine. This HPV informations should be communicated to various target groups. Among them education of health professionals is a priority as they are the first contact of women and girls. Moreover HPV infection has significant social and psychological consequences which can be tackled by communication skill of health care providers. Unfortunately health care providers understanding about HPV issues has lagged behind the scientific and technical advances in the field ${ }^{5}$. Provider endorsement is the key determinant of HPV vaccine acceptance by parents and potential vaccine recipients ${ }^{6}$. The present study aimed to-

(a) Identify knowledge gap of health care providers on HPV related issues.

(b) Educate health care providers on HPV related issues including vaccination.

(c) Determine improvement in knowledge of Health care providers on HPV related issues after education. 
The impact of above intervention will result in strengthening capacity of Health Care providers delivering services to women and adolescents in Medical Colleges to provide prevention services for cervical cancer integrating screening, HPV testing and vaccination.

\section{Methodology :}

The study was an intervention study with pre and post test design. There was no control group for comparison. Intervention was given by advocacy on four different aspects of HPV issues. The advocacy materials and questionnaire were field tested in BSMMU immediately before the workshops. The knowledge level of the participants before and after intervention was compared to find out-

(a) Knowledge gap of participants on HPV related issues and

(b) Impact of intervention in upgradation of knowledge on HPV related issues.

Knowledge gap of participants were found by looking at the pretest score and identifying the areas of knowledge deficiency while improvement of knowledge was found by making a comparison between pretest and post test score.

Duration of the study:

The study was of 12 months duration from July 2007 to June 2008. First four months was the preparatory phase for development of advocacy materials and questionnaire and field testing, next five months for advocacy workshop in three different venues and last three months was for compilation of data and report writing.

Place of study:

Venue selection was done purposively to cover selected health care providers of government and private medical college. The venues for advocacy were in Dhaka Medical College, Shaheed Shuhruwardy Medical College and Bangladesh Medical College. 10 participants from Holy Family Red Crescent Medical College joined the workshop in Bangladesh Medical College.

Details of the activities conducted :

1. Development of Advocacy materials and Questionnaire :
Advocacy materials to educate health care providers on HPV related issues including vaccination was developed by a technical group. The objective was to create awareness of participants about HPV related issues including vaccination and strengthen their capacity to provide screening for cervical cancer integrating HPV testing. The four presentations in advocacy workshop were

1. Overview of HPV in relation to cervical cancer

2. Achievement and limitations of pap's smear

3. Clinical application of HPV testing

4. HPV vaccine

A self administered questionnaire containing fifty questions and each carrying one marks were arranged for pre and post test covering the four presentation. Pretest identified the knowledge gap of health care providers on HPV related issues. Post test determined the improvement of knowledge of the same participants on HPV related issues. The presentations and questionnaire was field tested in BSMMU, Dhaka.

2. Advocacy workshops :

Three advocacy workshop were conducted in three different venues of Dhaka. Each workshop was chaired by the Head of the Dept. of Obstetrics and Gynaecology of that venue. The principal or the Director of that venue was the chief guest.

Target Audience :

A total of 106 participants participated in three advocacy workshop. In each advocacy workshop 30-40 health care providers dealing with the service delivery of women and adolescent girls were the target audience. They included obstetricians and gynaecologists, paediatrician, pathologist and microbiologist. These participants were selected at each venue according to convenience.

Data Management and Statistical Analyses

Data were entered using the SPSS Data Entry Programme. The knowledge level of the study participants was assessed by counting the number of correct answers. Pre- and post-test scores were checked for skewness and logarithmic transformed (base 10) were applied where necessary to normalise the data. Statistical tests used to determine the association between characteristics of the study participants and preand post-test score included Student t-test and one-way 
analysis of variance(ANOVA). A result was considered significant at a $p$ value level $<0.05$. To find the influence of intervention on knowledge level by paired t-test and repeated measure analyses was done. The analyses were carried out using the Statistical Package for Social Sciences (SPSS) version 14.0.

\section{Results}

Background characteristics

Almost equal number of medical graduates working in three medical colleges, Shaheed Shuhruwardy Medical College (35), Dhaka Medical College (39) and Private Medical College (32) were recruited in the study.

Their background characteristics are shown in Table 1. Most of them were females (93.4\%) and working in the department of Obstetrics and Gynaecology (90.5\%). Of the total participants, $23.8 \%$ had more than one postgraduation qualification. One-third of them did not complete post-graduation and about $46 \%$ were working as junior level doctors (medical officer \& assistant registrar). The participants were between the age of 27 and 55 years with a mean (SD) of 39.38 (7.40) years and median of 38 years.

Knowledge level of study participants about Human Papiloma Virus (HPV)

A tool was developed with fifty questions having two types of responses, true or false to assess the knowledge level of study sample. A pretest was taken from one hundred and six participants who enrolled in the intervention. Of them five did not appear for the posttest.

There was wide gap in HPV related knowledge among study participants. The pretest score was 28.09 out of 50 . Though $90 \%$ could correctly identify HPV as the cause of cervical cancer, but $72 \%$ lacked the knowledge about HPV persistence and $46 \%$ incorrectly stated the association of HPV types with cervical cancer. $60 \%$ were ignorant about different methods of HPV testing. Big knowledge gap was observed in the clinical application of HPV testing. Only 48\% participants knew that most genital HPV infections cleans without treatment. Wide knowledge gap was also observed in the natural history of HPV and cytology based screening among the participants. The health care providers were more unaware about issues related to HPV vaccines.
Change in knowledge level after intervention

One hundred and one participants scored, on average, 28.20 in the pre-test which increased by, on average, 10 in the post-test. This difference was tested by paired ttest and found significant. (Table:2).

\section{Table-I}

\section{Background characteristics of study participants}

\begin{tabular}{|c|c|c|}
\hline Characteristics & Frequency & Percent \\
\hline \multicolumn{3}{|l|}{ Sex } \\
\hline Male & 7 & 6.6 \\
\hline Female & 99 & 93.4 \\
\hline \multicolumn{3}{|l|}{ Age in years } \\
\hline$<30$ & 7 & 6.7 \\
\hline $30-34$ & 25 & 24.0 \\
\hline $35-39$ & 25 & 24.0 \\
\hline $40-44$ & 18 & 17.3 \\
\hline $45-49$ & 15 & 14.5 \\
\hline $50+$ & 14 & 13.5 \\
\hline \multicolumn{3}{|l|}{ Specialty } \\
\hline Obstetrics \& Gynaecology & 97 & 90.5 \\
\hline Pathology \& Microbiology & 4 & 3.8 \\
\hline Paediatrics & 5 & 4.7 \\
\hline \multicolumn{3}{|l|}{ Position } \\
\hline Medical Officer & 48 & 45.7 \\
\hline Consultants & 27 & 25.7 \\
\hline Teaching Position & 30 & 28.6 \\
\hline \multicolumn{3}{|l|}{ Post graduation } \\
\hline No post graduation & 36 & 34.3 \\
\hline Diploma & 13 & 12.4 \\
\hline Post graduation & 56 & 53.3 \\
\hline
\end{tabular}

Table-II

\begin{tabular}{lccccc}
\multicolumn{5}{c}{ Differences in knowledge level in overall pre and } \\
post-test score \\
Score & N & Mean & SD & t & p \\
\hline Pre-test & 101 & 28.20 & 4.83 & -16.9 & $<<0.001$ \\
Post-test & 101 & 38.60 & 3.84 & & \\
\hline
\end{tabular}

Figures 2 and 3 shows the distribution of pre and posttest score respectively. As both the data were skewed, they were log transformed for further analyses. 


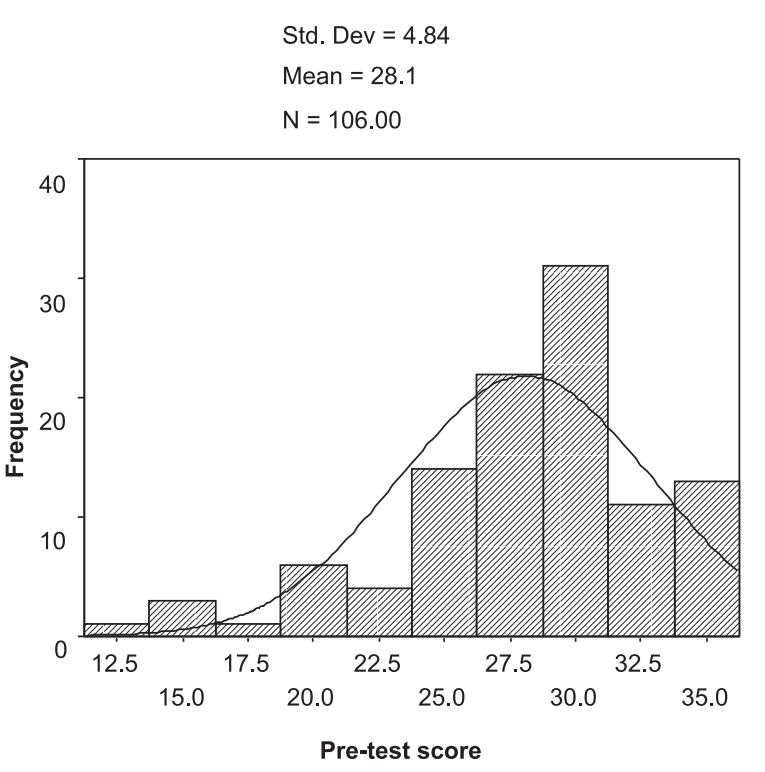

Fig.-1: Score obtained in the pre-test

Knowledge level about Human Papiloma Virus (HPV) by the medical colleges

No significant difference was observed in the pre-test and post-test score between the participants of three medical colleges by one-way ANOVA. (Table : 3 )

Knowledge level about Human Papiloma Virus (HPV) by the speciality of participants

The independent sample t-test found that the participants working in Obstetrics and Gynaecology obtained higher

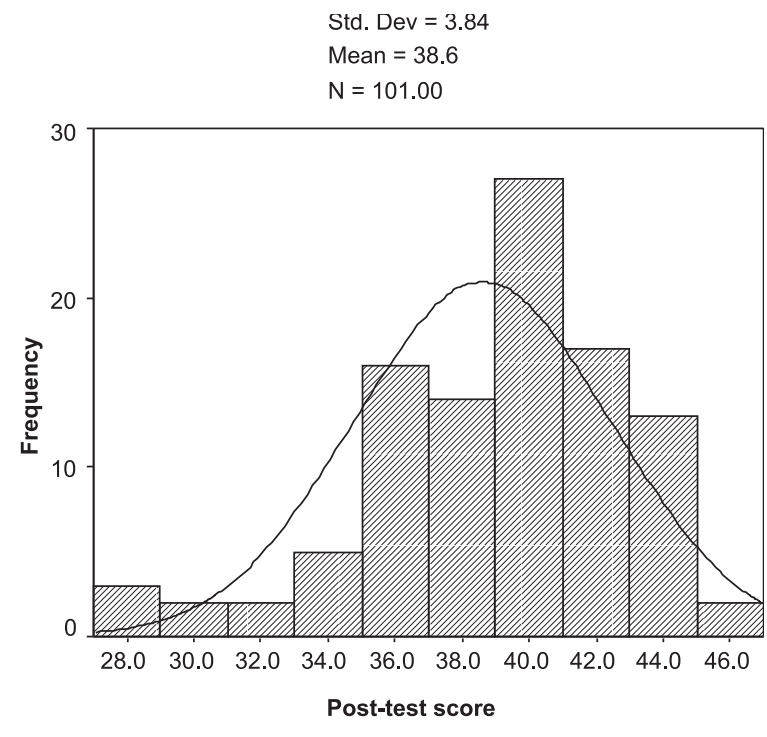

Fig.-2: Score obtained in the post-test

score in the pre-test but no significant difference was found in post-test score. The observation included only 10 participants from other specialities.(Table: 4)

Knowledge level about Human Papiloma Virus (HPV) by the post-graduation status of participants

One-way ANOVA test did not show any significant difference in pre-and post-test score between the postgraduation status of the participants. (Table:5)

Table-III

Pre and post-test score of knowledge level by participants of different medical colleges

\begin{tabular}{|c|c|c|c|c|c|c|c|c|}
\hline \multirow[t]{2}{*}{ Medical College } & \multicolumn{4}{|c|}{ Pre-test score } & \multicolumn{4}{|c|}{ Post-test score } \\
\hline & $\mathrm{n}$ & Mean & $\mathrm{SD}$ & $\overline{\mathrm{p}}$ & $\mathrm{n}$ & Mean & SD & $\mathrm{p}$ \\
\hline$\overline{\mathrm{SSMC}}$ & 35 & 27.31 & 5.81 & & 33 & 38.46 & 4.64 & \\
\hline DMC & 39 & 27.90 & 4.68 & ns & 38 & 38.47 & 2.64 & ns \\
\hline PMC & 32 & 29.19 & 3.68 & & 30 & 38.93 & 4.26 & \\
\hline
\end{tabular}

SSMC- Shaheed Shuhruwardy Medical College; DMC- Dhaka Medical College; P- Private Medical College

Table-IV

Pre and post-test score of knowledge level by the speciality

\begin{tabular}{|c|c|c|c|c|c|c|c|c|}
\hline \multirow[t]{2}{*}{ Speciality } & \multicolumn{4}{|c|}{ Pre-test score } & \multicolumn{4}{|c|}{ Post-test score } \\
\hline & $\mathrm{n}$ & Mean & $\mathrm{SD}$ & $\mathrm{p}$ & $\mathrm{n}$ & Mean & $\mathrm{SD}$ & $\mathrm{p}$ \\
\hline Gynaecology & 96 & 28.43 & 4.61 & $<0.05$ & 91 & 38.76 & 3.65 & \\
\hline Others & 10 & 24.90 & 6.05 & & 10 & 37.20 & 5.33 & ns \\
\hline
\end{tabular}


Table-V

Pre and post-test score of knowledge level by the post-graduation status

\begin{tabular}{|c|c|c|c|c|c|c|c|c|}
\hline \multirow[t]{2}{*}{ Post-graduation } & \multicolumn{4}{|c|}{ Pre-test score } & \multicolumn{4}{|c|}{ Post-test score } \\
\hline & $\mathrm{n}$ & Mean & SD & $\mathrm{p}$ & $\mathrm{n}$ & Mean & SD & $\mathrm{p}$ \\
\hline No post-graduation & 36 & 28.61 & 4.67 & & 36 & 37.69 & 3.16 & \\
\hline Diploma & 13 & 27.46 & 5.88 & ns & 13 & 38.15 & 2.58 & ns \\
\hline Postgraduates & 56 & 28.00 & 4.75 & & 51 & 39.39 & 4.43 & \\
\hline
\end{tabular}

\section{Discussion:}

The successful introduction of any new vaccine depends on many factors, including the need for broad based support from policy makers, health care professional and general public ${ }^{7,8}$. Understanding of Health care providers regarding HPV infection is low in developing world. There is confusion about how HPV leads to cervical cancer HPV testing and its integration in the screening for cervical cancer. Wide knowledge gap is evident in areas of HPV vaccination and its incorporation into cervical cancer prevention program. Therefore effective HPV education and training programs for health care providers must be in place to promote the acceptability of HPV Vaccination. ${ }^{9,10}$. Moreover health care providers communication skill also need to be upgraded to facilitate effective discussions with vaccine recipients and their parents.

Health care providers are key audience for HPV vaccine related communication and training. They include persons involved in delivering HPV vaccine through immunization services, adolescent health centres, women's health centre, cancer care centres, school health programs and private pharmacies. They need to know how and why HPV vaccine is important. Thus Health care providers need training, education and communication tools to facilitate effective discussions with their parents, such as simple talking and visual aids.

In this study HPV related knowledge was not up-todate among health care providers. The pretest score was 28-09 out of 50. The findings of knowledge gap among health care providers in this survey as evident in the pretest score was consistent with the findings of other surveys conducted in United: States: ${ }^{10,11,12}$. However intervention in the from of advocacy brought improvement in the knowledge level of health care providers. The post test score was 38.60 , and there was an improvement of 10 score from the pretest which was found significant $(\mathrm{p}<0.001)$ within the subjects. Significant improvement was observed in issues like natural history of HPV, HPV persistence, association of HPV types in cervical cancer, HPV DNA testing. There was still incorrect response in the posttest in clinical application of HPV testing and HPV vaccination. More details discussion on the issues might clear the confusion among the participants. The improvement in knowledge among participants on HPV related issues in this survey clearly proves the importance of awareness raising program in HPV infection and vaccination.

\section{Conclusion and Recommendation:}

This study clearly shows the knowledge gap of health care providers on HPV related issues. To overcome this gap large scale surveys on General Practioners, Primary care clinicians, Obstetricians and Gynaecologists, Pediatricians, Pathologists, Cytologists, Microbiologists and Health care providers from other disciplines should be conducted to identify knowledge gaps. Interventions in the from of CMEs, Seminars, symposium should be organized with health care providers to provide updated informations on HPV related issues. Moreover the health care providers should have easy access to training curricula, clinical decision support tools to facilitate patients counselling and education. The interested Health care providers should be offered access to expensive peer- reviewed journals and prints downloaded from web. All these are few options which will minimize the knowledge gap of Health care providers on issues of HPV and vaccine.

\section{Acknowledgement :}

We are grateful to Bangladesh College of Physicians and Surgeons (BCPS) for financially supporting the study. 


\section{Referenecs:}

1. Ferlay J, Bray F, Pisani P, Parkin DM, GLOBOCAN 2002. Cancer Incidence, Mortality and Prevalenec world wide. IARC cancer Base No 5 version 2.0, Lyon: IARC, Press: 2004.

2. Bosch Fx, Manos MM, Munoz N, Sherman M, Jausen A, Peto J etal. The IBSCC study group. Prevalenec of Human Papilloma Virus in cervical cancer, a world wide perspeative, J Nat I cancer Inst 1995; 87: 796 - 802.

3. Walboomers JM, Jacobs MV, Manos MM, Bosch Fx, Kummer JA, Shah KV et al. Human papillomavirus is a necessary cause of cervical cancer world wide, J Pathol 1999; 189: 12-9.

4. Munoz N, Bosch Fx, Castellsaque X, Diaz M, de Sanjose S, Hummooda D et al . Against which Human papillomarirus types shall we vaccinate and screen ? The International Perspcetive Int J cancer 2004: 111: 278 - 85.

5. Auhang R, Wright Jr Tc, Smockl, Coldie SJ. Women's desire information about Human Papillomarius. Cancer 2004, 100 (2) : $315-20$.

6. Zimet GD, Improving adolescent health : focus on HPV vaccine acceptance, J Adolescent Health 2005; 97 (supply 6) : $517-23$.
7. Strecfland PH. Introduction of a HPV vaccine in developing countries, social and cultural dimension. Vaccine 2003:21 (13-13):1304-9.

8. Bresee JS. Humelman E, Nelson EA, Glass RI, Rotavirus in Asia: the value of surveillance for informing decisions about the introduction of new vaccine. J Infect Dis 2005; 192 (suppl.1: S1-5).

9. Khan JA, Rosenthal SL, Human T, Bernstein DI. Attitudes about human papillomavirus vaccine in young women. Int $\mathrm{J}$ STD $2003 ; 314(5) ; 300-6$.

10. Liazcano - Ponce E, Rivera L, Avillo - Santillan E, Salmeron J , Hermandez - Avila M, Munoz N . Accetability of a Human papillomarvirus (HPV) trial vaccine among mothers of adolescents in Cuernavaea, Mexico. Arch Med Res 2001; 32 (3): $243-7$.

11. Centers for Disease Control and Prevention, HPV communication, Outreach, Report No 2001 - Q.00133 (E40), Atlanta, GA, 2002.

12. Centers for Disease Control and Prevention ( CDC) . Final report on HPV clinical survey : knowledge, Attitudes , Practices about Genital HPV infection and related conditions. Contract No. GSH, Atlanta, GA 2005. 